\title{
Neurotrophin NT3 promotes ovarian primordial to primary follicle transition
}

\author{
Eric Nilsson, Gretchen Dole and Michael K Skinner \\ Center for Reproductive Biology, School of Molecular Biosciences, Washington State University, Pullman, \\ Washington 99164-4234, USA \\ Correspondence should be addressed to M K Skinner; Email: skinner@wsu.edu
}

\begin{abstract}
Neurotrophins are growth factors that are known to have a role in promoting cell survival and differentiation. The focus of the current study is to examine the role of neurotrophins in regulating ovarian primordial follicle development. Ovaries from 4-day old rats were placed into organ culture and cultured for 10 days in the absence or presence of neurotrophin-3 (NT3), brain-derived neurotrophic factor (BDNF), or nerve growth factor (NGF). Treatment of ovaries with NT3 resulted in a significant $(\boldsymbol{P}<\mathbf{0 . 0 1})$ increase in primordial follicle development (i.e. primordial to primary follicle transition). Treatment with BDNF at high doses of 100-250 ng/ml also significantly $(\boldsymbol{P}<0.01)$ increased primordial follicle development, but NGF had no effect. Immunohistochemical studies determined that NT3 was present in granulosa cells, interstitial tissue, and in the oocytes of primordial and primary follicles. The NT3 receptor NTRK3 was present in oocytes at all stages of development. Analysis of ovaries that contain predominantly primordial follicles demonstrated the transcripts for NT3, NTRK3, NGF, and the BDNF/neurotrophin-4 (NT4) receptor NTRK2 are expressed, while BDNF, NT4, and the NGF receptor NTRK1 are not detectable. Inhibition of the NTRK3 receptor with the tyrphostin AG 879 resulted in oocyte death and a significant $(P<0.01)$ reduction in follicle pool size. Inhibition of the NTRK receptors with K252a slowed primordial to primary follicle transition. A microarray analysis demonstrated that a small number of genes were differentially expressed after NT3 treatment. Observations indicate that the neurotrophin NT3, acting through the NTRK3 receptor in oocytes, promotes the primordial to primary follicle transition. Reproduction (2009) 138 697-707
\end{abstract}

\section{Introduction}

Neurotrophins are paracrine signaling molecules that are well known for their role in promoting survival and differentiation of neuronal cells. In mammals, these signaling factors include nerve growth factor (NGF; Levi-Montalcini et al. 1996), brain-derived neurotrophic factor (BDNF; Leibrock et al. 1989), neurotrophin-4 (NT4; Berkemeier et al. 1991, Ip et al. 1992), and neurotrophin-3 (NT3; Hohn et al. 1990, Maisonpierre et al. 1990, Rosenthal et al. 1990). High-affinity neurotrophin receptors (NTRs) are transmembrane tyrosine kinase receptors that belong to the NTRk proto-oncogene family. NGF binds to the NTRK 1 receptor, BDNF and NT4 bind to NTRK2, and NT3 binds to NTRK3 (reviewed in Segal (2003)). All these neurotrophins also bind to a low-affinity receptor, P75 NTR (Chao et al. 1986, Johnson et al. 1986, Segal 2003).

In addition to neuronal cell functions, neurotrophin signaling events also have important roles in non-neural tissues (Kawaguchi-Manabe et al. 2007, Papatsoris et al. 2007, Peters et al. 2007, Freund-Michel \& Frossard 2008, Nico et al. 2008). Previously, we have observed that Nt3 and Ntrk3 genes are expressed in developing neonatal rat ovaries and are influenced by factors that regulate primordial follicle development (Kezele et al. 2005b, and unpublished data). The focus of the current study is to examine the role of neurotrophins in ovarian follicle development.

In rodents, primordial follicles are formed between the day of birth and several days of age in a process known as primordial follicle assembly (Hirshfield 1991, Hirshfield \& DeSanti 1995, Skinner 2005). Primordial follicles consist of a single oocyte that is arrested in prophase of the first meiotic division and that is surrounded by flattened pregranulosa cells. When a primordial follicle leaves the arrested state and begins to develop, the flattened pregranulosa cells proliferate and become cuboidal, and the oocyte begins to enlarge. This process is known as the primordial to primary follicle transition. Once a primordial follicle leaves the arrested state it will either continue to grow until the oocyte is released at ovulation or the follicle undergoes apoptosis and atresia (Peters et al. 1975, Hirshfield 1991, Rajah et al. 1992). Several growth factors have been identified that regulate primordial to primary follicle transition by paracrine and autocrine signaling pathways including: kit ligand $(\mathrm{KL})$; leukemia inhibitory factor (LIF); bone morphogenetic protein 4 (BMP4); BMP7; platelet-derived growth factor 
(PDGF); basic fibroblast growth factor (bFGF); and glial-derived neurotrophic factor (GDNF; Fortune 2003, Skinner 2005, Visser \& Themmen 2005, Dole et al. 2008). Anti-Müllerian hormone/Müllerian inhibitory substance and stromal-derived factor-1 (SDF-1/ CXCL12) inhibit primordial to primary follicle transition (Ikeda et al. 2002, Holt et al. 2006, Nilsson et al. 2007). Once the supply of follicles in the ovary is exhausted reproduction ceases and, in humans, women enter menopause (Gosden et al. 1983, Richardson et al. 1987, Faddy 2000). A thorough understanding of this process will lead to therapies for ovarian disease and control of the transition to menopause.

Previous research has characterized the expression of neurotrophins in ovarian follicle cells. At the developmental period that primordial follicles are being formed (i.e. primordial follicle assembly), low-affinity P75 NTR receptor expression increases, NGF and NTRK1 expression decreases, and NT4 along with NTRK2 mRNA expression increases (Dissen et al. 1995). In mice, P75 NTR protein is expressed in interstitial/stromal cells of ovaries containing primordial and developing follicles (Dissen et al. 2001). Expression of the NGF receptor NTRK1 was detected in some stromal cells, and NTRK1 was abundant in the granulosa cells and oocytes of primordial and primary follicles in mice (Dissen et al. 2001). In humans, NT4 and BDNF protein are expressed in oocytes of primordial and developing follicles, with some granulosa cells also stained. The NTRK2 receptor for NT4 and BDNF is strongly expressed in granulosa cells of primordial and early developing follicles in humans, with some expression in oocytes (Harel et al. 2006). NT3 expression has been previously detected in the granulosa cells of growing follicles in rats (Ernfors et al. 1990). In humans, both NT3 and NTRK3 were detected in the granulosa cells of antral pre-ovulatory follicles and NTRK3 was detected in oocytes (Seifer et al. 2006). However, little has been reported about the expression or action of neurotrophins or NTRK receptors in arrested primordial follicles or early stage developing follicles.

The objective of the current study is to test the actions of the neurotrophins NT3, BDNF, and NGF in promoting primordial to primary follicle transition. In addition, the expression patterns of NT3 and NTRK3 in primordial and developing follicles were investigated. A better understanding of the regulation of this critical reproductive process will lead to better understanding and therapies for some infertility disorders (i.e. premature ovarian failure), or potentially to extend the reproductive lifespan of domestic animals, as well as to control of the menopausal transition in women.

\section{Results}

Ovaries from 4-day old rats were placed into a wholeovary organ culture system and cultured for 10 days with or without treatments of NT3, BDNF, or NGF. The ovaries were then fixed, sectioned, stained, and examined microscopically for differences in the proportion of developing versus quiescent (primordial) follicles. Effects on primordial to primary follicle transition were determined. Treatment of ovaries in culture with $50 \mathrm{ng} / \mathrm{ml} \mathrm{NT3}$ resulted in a significant $(P<0.01)$ increase in the proportion of developing follicles (i.e. increased primordial follicle transition; Fig. 1A). Treatment with
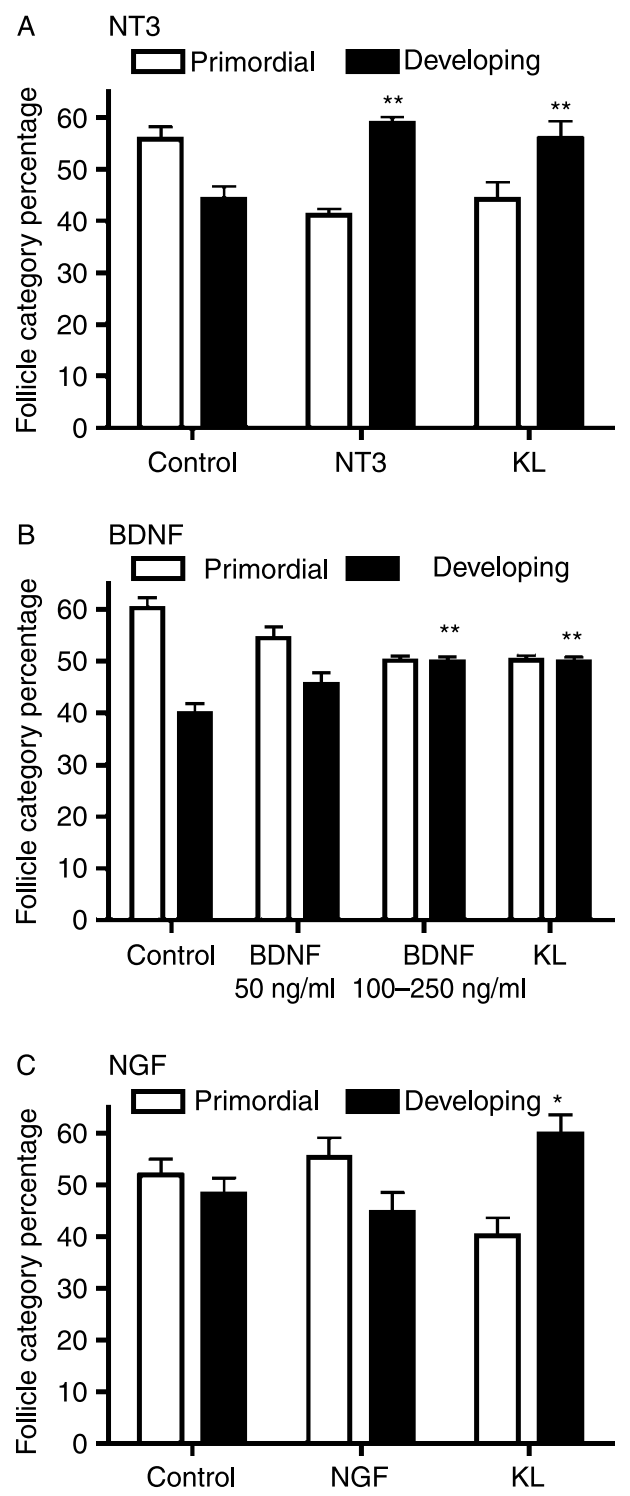

Figure 1 Follicle development (follicle category percentage) in cultured rat ovaries treated with NT3, BDNF or NGF. Postnatal 4-day (P4) old rat ovaries were cultured for 10 days in the absence or presence of: (A) NT3 (50 ng/ml); (B) BDNF (50 or $250 \mathrm{ng} / \mathrm{ml}) ;(C)$ NGF $(50 \mathrm{ng} / \mathrm{ml})$; or KL $(50 \mathrm{ng} / \mathrm{ml})$. Follicles were classified as primordial or developing. $\mathrm{KL}$ was used as a positive control and has previously been shown to stimulate follicle development. A minimum of three different experiments in replicate were performed with the mean \pm s.E.M. presented and asterisks indicating a statistical difference from control with ${ }^{*} P<0.05$ and ${ }^{* *} P<0.01$ by Dunnet's post-hoc test after a significant ANOVA result. 
BDNF at higher doses of $100-250 \mathrm{ng} / \mathrm{ml}$ also significantly $(P<0.01)$ increased the proportion of developing follicles (Fig. 1B), although less was seen with NT3, and no effect was observed at lower BDNF concentrations. Treatment with NGF had no effect on primordial to primary follicle transition (Fig. 1C). Treatment with $\mathrm{KL}$, a known stimulator of primordial follicle transition (Parrott \& Skinner 1999), was used as a positive control (see Materials and Methods). None of these neurotrophin treatments caused a change in total oocyte number per section (i.e. caused a change in follicle pool size) compared to untreated controls (data not shown).

Immunohistochemistry was performed to determine where NT3 and NTRK3 proteins were localized in the rat ovary. In cultured neonatal rat ovaries, NT3 was present in granulosa cells, interstitial tissue, and in the oocytes of primordial and primary follicles (Fig. 2A). NT3 was less apparent in the oocytes of larger developing follicles (Fig. 2A). Since follicles in cultured ovaries undergo transition and growth, it is expected that cell type distribution of ligand and receptor will be similar to that in vivo. In adult rat ovaries, NT3 was detected in all cell types of larger developing follicles (Fig. 2E). However, NT3 staining was not uniform across all cell types of the adult ovary (Fig. 2E, inset), indicating that staining was specific. NTRK3 protein was present in oocytes at all stages of development, as well as in theca cells in large antral and pre-antral follicles (Fig. 2B and F). Interestingly, in early stage follicles NT3 was more apparent in oocyte nuclei, while the NTRK3 receptor was more apparent in oocyte cytoplasm.

RNA from whole 4-day old rat ovaries was evaluated for the presence of Nt3, Nt4, Ngf, and Bdnf transcripts, and for the NTRs Ntrk1, Ntrk2, and Ntrk3 (Fig. 3). Fourday old rat ovaries have predominantly primordial follicles present. Results of RT-PCR-based detection experiments indicated that the transcripts for Nt3, Ngf, Ntrk2, and Ntrk3 were present, and that transcripts for $\mathrm{N} t 4$ and Ntrk1 were not detectable. The presence of $B d n f$ was negligible (Fig. 3). These observations suggest that an intact NT3/NTRK3 signaling pathway is important for primordial follicle function.

In order to test the effect of blocking signaling from endogenous ovarian NT3, ovaries from 4-day old rat pups were cultured in the presence of the tyrphostin AG 879 , which is an inhibitor of NTRK3 receptor signaling. In a previous study using a similar organ culture system, $20 \mu \mathrm{M}$ AG 879 was found to be effective at blocking the effects of NT3 on rat testis development (Cupp et al. 2003). Surprisingly, in the current study, AG 879 treatment in vitro resulted in oocyte death and a significant $(P<0.01)$ reduction in the number of oocytes per ovarian cross-section, indicating a reduction in follicle pool size (Fig. 4A). This effect occurred at AG 879 treatment concentration of $>4 \mu \mathrm{M}$. At the $0.8 \mu \mathrm{M}$ dose, AG 879 had no effect on follicle pool size, and also had no effect on primordial to primary follicle transition
(Fig. 4B). TUNEL analysis of ovary sections after culture showed an increase in the number of positive labeled oocytes with AG 879 treatment, indicting an increase in apoptotic oocytes (Fig. 5).

This in vitro observation was extended with an in vivo treatment of postnatal female rats. Treatment of 5-day old and $\sim 25$-day old rats in vivo with 7.6 and $6.7 \mathrm{mg} / \mathrm{kg}$ per

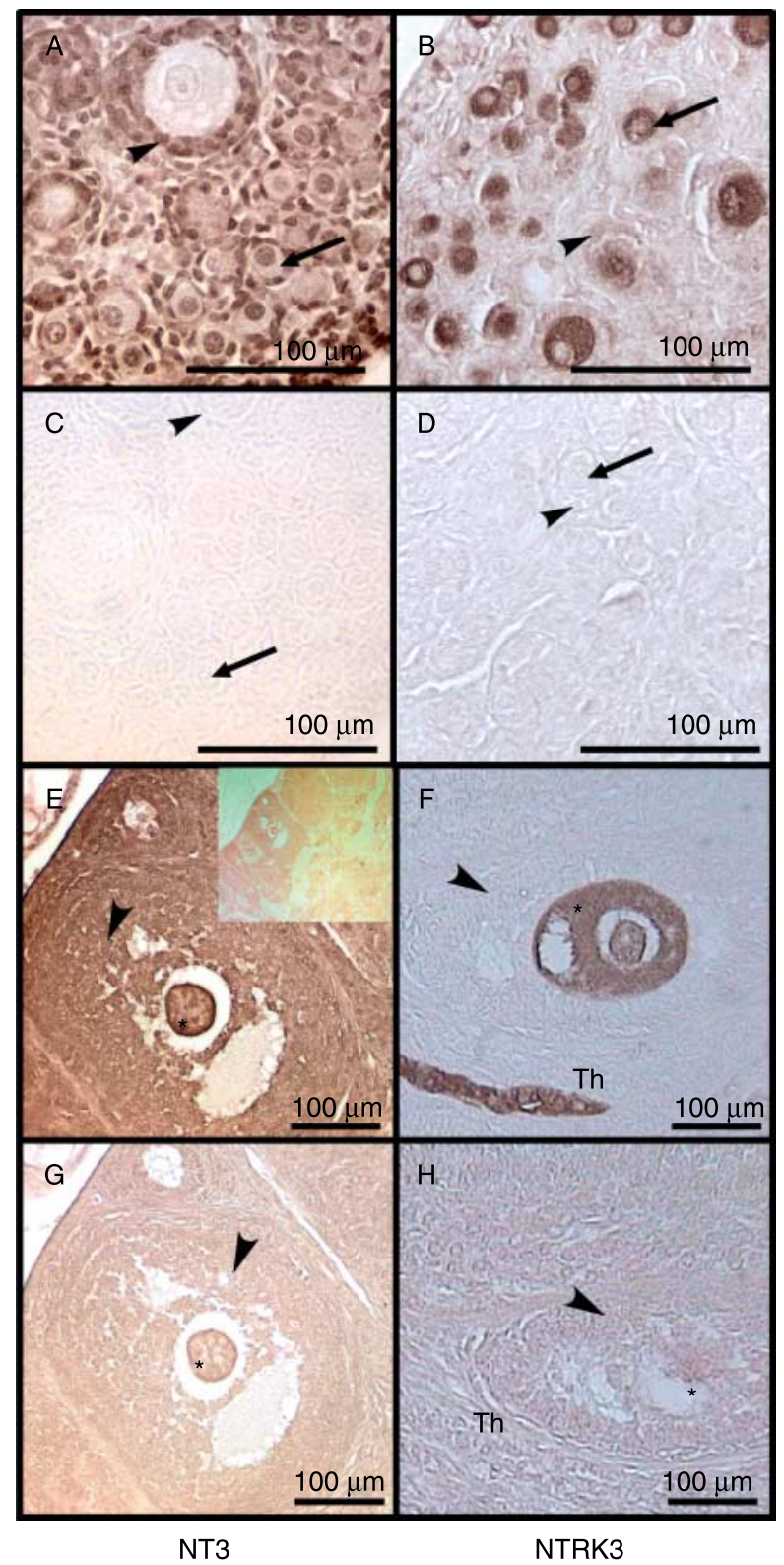

Figure 2 Immunohistochemistry of follicles of rat ovaries. Brown indicates the presence of the specified protein. (A-D) Postnatal 4-day (P4) old rat ovaries cultured for 10 days. (A) Anti-NT3 IgG; (B) antiNTRK3 IgG; (C) non-immune rabbit IgG; (D) non-immune rabbit lgG. $(\mathrm{E}-\mathrm{H})$ Adult rat ovaries. (E) Anti-NT3 IgG with inset of lowermagnification image; (F) anti-NTRK3 IgG; (G) non-immune IgG; $(\mathrm{H})$ non-immune IgG. Asterisk indicates oocyte cytoplasm; arrowheads indicate granulosa cells; arrows indicate oocyte; Th indicates theca cells. Observations are representative of a minimum of three different experiments. 
S2 Nt4 Nt3 Ngf Bdnf Ntrk1 Ntrk2 Ntrk3

\begin{tabular}{|r|c|c|c|c|c|c|c|c|}
\hline P4 ovary & & & - & - & & & & \\
\hline Positive control & & & & - & - & & - & \\
\hline Positive control tissue & $\mathrm{t}$ & $\mathrm{t}$ & $\mathrm{t}$ & $\mathrm{p}$ & $\mathrm{p}$ & $\mathrm{t}$ & $\mathrm{b}$ & $\mathrm{t}$ \\
\hline
\end{tabular}

Figure 3 Neurotrophin and NTRK receptor expression in postnatal 4day (P4) old rat ovaries. RNA from P4 whole rat ovaries was screened for neurotrophin and NTRK expression. PCR was performed on ovary samples as well as tissues known to express the genes of interest $(t=4$ day old testes; $p=$ adult pituitary; $b=$ adult whole brain). S2 is a constitutively expressed rRNA. Data is representative (brain and testis) of a minimum of three different experiments.

day AG 879 respectively (the equivalent of 23.9 and $23.5 \mu \mathrm{M}$ doses) for 5 days did not result in detectable changes in follicle development rates or oocyte death and follicle pool size compared to controls of the same age (Fig. 6 and 25-day old data not shown). Higher doses of AG 879 resulted in dose-dependant rat mortality (data not shown). Therefore, no in vivo manipulation of primordial follicle pool size was observed.

Organ culture experiments were performed using the tyrphostin K252a which inhibits signaling of all NTRK receptors, including NTRK3. K252a at $200 \mu \mathrm{M}$ inhibited primordial to primary follicle transition in cultured ovaries (Fig. 7; $P>0.05$ by Student's $t$-test). Morphological examination of hematoxylin/eosin stained K252a-treated ovary sections showed that some developing follicles had an unhealthy appearance, with expanded oocyte nuclei, irregular granulosa cell layers, or indistinct oocytes (data not shown). However, there was no significant change in the total number of follicles present in K252a-treated ovaries.

A microarray analysis was performed in order to determine what pathways and cellular processes were affected by NT3 signaling in primordial follicles. Ovaries of 4-day old rats were cultured for 2 days with or without $50 \mathrm{ng} / \mathrm{ml} \mathrm{NT3}$ and RNA was isolated from the ovaries for use in microarray analysis. A 2-day treatment was used to observe early event signaling events independent of developmental changes observed after 10 days of culture. Table 1 contains a list of the genes differentially expressed after NT3 treatment. A relatively small number of genes (18 excluding expressed sequence tags) were found to be differentially expressed according to the criteria described in Materials and Methods. These included several genes known to have functions in plasma membrane mobility and function as well as some known to be important for developmental processes, see Table 1.

\section{Discussion}

Neurotrophins have been shown to be present in ovaries, and when neurotrophin genes are eliminated in knockout mice, follicle formation and development is affected (Dissen et al. 2002). However, it is difficult to isolate the effects of a gene knockout phenotype to a specific stage of follicle development. Therefore, in the current study experiments were performed to clarify and further determine the roles played by neurotrophins in regulating primordial to primary follicle transition. Treatment of ovaries in culture with NT3 resulted in a significant increase in developing follicles (Fig. 1A). mRNA for Nt3 and its receptor Ntrk3 are expressed in ovaries at the time of the first wave of primordial to primary follicle transition (Fig. 3). NT3 protein was present in granulosa cells, interstitial tissue, and in the oocytes of primordial follicles (Fig. 2). NTRK3 protein was present in oocytes at all stages of development (Fig. 2). Observations indicate that NT3 from different ovarian cell types promotes the primordial to primary follicle transition by signaling through the NTRK3 receptors present in oocytes.

BDNF treatment of ovaries in culture was able to promote the primordial to primary follicle transition at higher dosage levels (Fig. 1B), but this may not be a physiologically relevant action for BDNF. This is because, at the time of primordial to primary follicle transition, BDNF is not expressed in rat ovaries, although its receptor NTRK2 is expressed (Fig. 3). Therefore, exogenous BDNF treatment has the potential to bind to
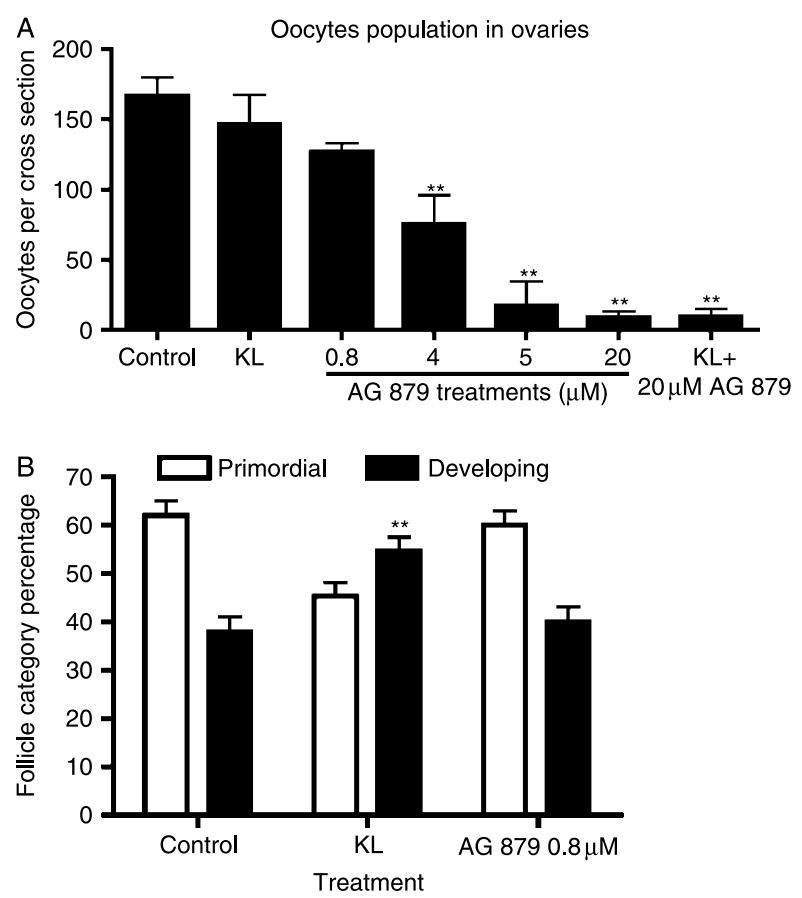

Figure 4 (A) Follicle pool size in AG 879 (NTRK3 tyrphostin) treated rat ovaries. Postnatal 4-day (P4) old rat ovaries were cultured for 10 days in the presence of AG 879 at different doses. The number of oocytes with visible nuclei was counted in the largest cross-sections through the center of each ovary. (B) Primordial to primary follicle transition in NTRK3 tyrphostin AG 879-treated postnatal 4-day (P4) old rat ovaries. $\mathrm{P} 4$ rat ovaries were cultured for 10 days in the absence or presence of $0.8 \mu \mathrm{M}$ AG 879 treatment or KL. This AG 879 dose did not cause a significant decrease in follicle pool size. $\left({ }^{* *}\right)$ indicates a significant $(P<0.01)$ difference compared to controls by Dunnett's multiple comparison post-hoc test after a significant ANOVA result. Data is the mean \pm S.E.M. from a minimum of three different experiments. 

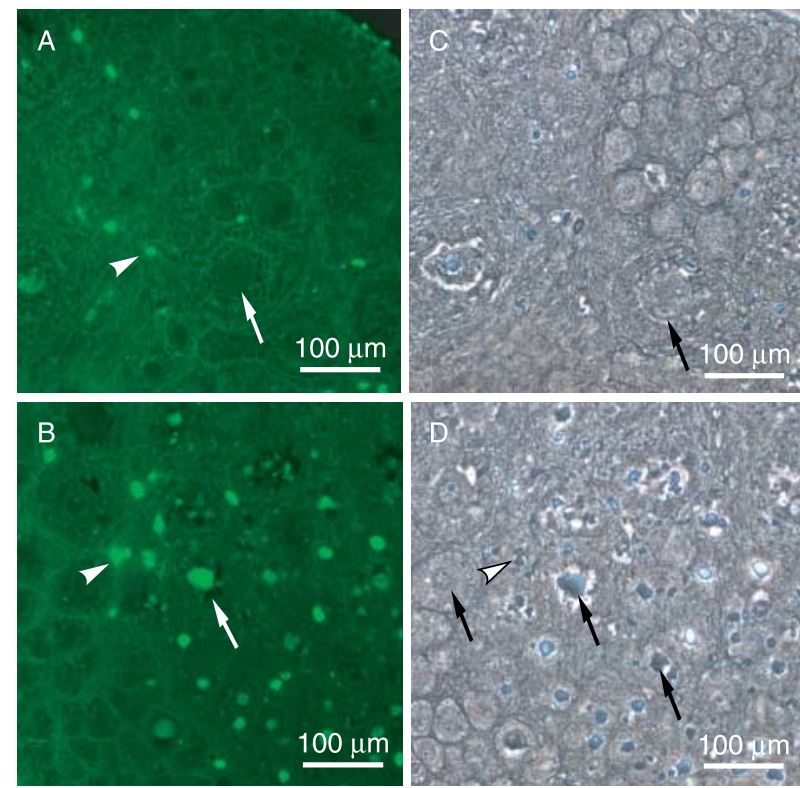

Figure 5 Apoptosis analysis of NTRK3 tyrphostin AG 879 treated ovaries. Postnatal 4-day (P4) old ovaries cultured in the absence or presence of AG 879 for 2 days were analyzed for incidence of apoptosis (i.e. TUNEL stain in A and B). A and C, Control; B and D, AG 879treated. Arrows indicate oocytes; arrowheads indicate stromal cells. The corresponding phase contrast images are shown (C and D). Observations are representative of a minimum of three different experiments.

endogenous NTRK2 and stimulate development, but there may be no BDNF produced in normal developing ovaries at this developmental period. The NTRK2 receptor probably has a role in larger developing follicles. In mice that are genetically lacking either NTRK2 expression or both BDNF and NT4 expression, primordial to primary follicle transition occurs, but growth of follicles beyond the primary stage is compromised (Paredes et al. 2004). This supports the idea that BDNF/NTRK2 signaling is not important for primordial follicle transition in rodents. However, humans are reported to have both BDNF and NTRK2 expression in primordial follicles (Harel et al. 2006). Further research is needed to determine what species differences exist in the neurotrophin signaling that helps regulate early follicle development.

NT3 has high-affinity binding to the NTRK3 receptor. However, under certain circumstances and during specific developmental time periods it has been shown that NT3 may activate the NTRK1 and NTRK2 receptors (Barbacid 1994, Davies et al. 1995, Huang et al. 1999, Dechant 2001). Since the Ntrk2 mRNA transcript is present in ovaries at this time, it is possible that some of the stimulation of primordial to primary follicle transition induced by NT3 treatment is due to NTRK2 activation. However, BDNF, a high-affinity ligand for NTRK2, was able only to stimulate follicle transition to a limited degree, suggesting that any contribution from NTRK2 activation is minor.
NGF was not shown to promote primordial to primary follicle transition (Fig. 1C). This matches the finding that mRNA for the NGF receptor Ntrk1 was not detectable in 4-day old rat ovaries containing predominately primordial follicles (Fig. 3). With no receptor present, NGF is not expected to be functional. However, a previous study by Romero et al. (2002) showed that NGF could induce FSH receptor expression in cultured 2-day old rat ovaries. NGF and NTRK1 expression decreases during the period of follicle assembly ( $0-5$ days of age) in rats (Dissen et al. 1995). Therefore, it appears that in the study by Romero et al. (2002), the NTRK1 receptors remaining at 2 days of age in rat ovaries could respond to NGF, but that in the current study, by 4 days of age, not enough NTRK1 remained to elicit a response to NGF in primordial follicles.

Immunohistochemistry results indicate that NT3 protein is present in both oocytes and the surrounding somatic cells of primordial follicles (Fig. 2). The NTRK3 receptor is present only in oocytes (Fig. 2). Therefore, NT3 signaling to its NTRK3 receptor can occur in either a paracrine or autocrine manner in primordial follicles. This is similar to the findings for GDNF, in which autocrine signaling occurs since both GDNF and its receptor GFR $\alpha 1$ are localized to primordial follicle
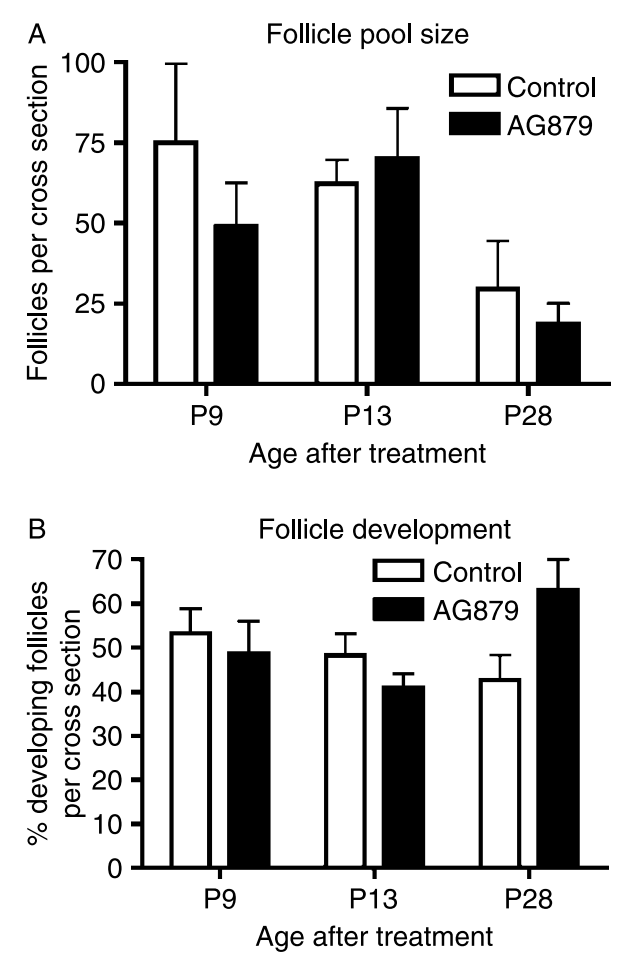

Figure 6 Treatment of 5-day old rat pups in vivo with the NTRK3 tyrphostin AG 879. Five-day old pups were injected s.c. daily for 5 days with $7.6 \mathrm{mg} / \mathrm{kg}$ per day AG 879. Pups were killed at postnatal day 9 (P9; $n=4)$, P13 $(n=5)$, and P28 $(n=2)$. Ovaries were evaluated as per Materials and Methods for (A) follicle pool size and (B) effect on primordial to primary follicle transition. AG 879 treatment resulted in no significant differences from controls of the same age. Data presented are the mean \pm S.E.M. 


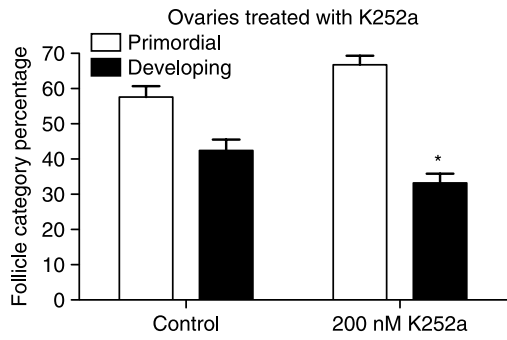

Figure 7 Primordial to primary follicle transition in postnatal 4-day (P4) old rat ovaries treated with the pan-NTRK receptor inhibitor tyrphostin K252a. P4 rat ovaries were cultured for 10 days in the presence or absence of $200 \mu \mathrm{M}$ K252a. Three experiments in replicate were performed with the mean \pm s.E.M. presented and $(*)$ indicating statistical difference $(P<0.05)$ from control by Student's $t$-test.

oocytes (Dole et al. 2008). This is also similar to the findings in human ovaries that the neurotrophins BDNF, NT4 and their receptor NTRK2 are each expressed in both oocytes and granulosa cells in larger developing follicles, so both autocrine and paracrine signaling is possible (Harel et al. 2006).

In order to test if primordial follicle transition would be slowed by interfering with NT3/NTRK3 signaling, ovaries in culture were treated with AG 879 , which is an inhibitor of NTRK3 function. At low doses there was no effect of AG 879 on primordial follicle transition (Fig. 4B). This could be because the dose was too low to inhibit NTRK3 or because of the compensatory nature of the network of growth factors that stimulates follicle transition. Other stimulatory growth factors may be able to compensate when NT3/NTRK3 signaling is inhibited, so that primordial follicle transition was not compromised in the cultured ovaries. Interestingly, treatment with increasing doses of AG 879 in cultured ovaries resulted in a marked decrease in oocyte number (Fig. 4A). This was due to increased apoptotic oocyte cell death (Fig. 5). This suggests that either NTRK3 signaling is important for maintaining oocyte viability, or that AG 879 has a cytotoxic affect on oocytes in particular that is independent of its actions on the NTRK3 receptor. AG 879 has been shown to also inhibit signaling through the ERBB2 (neu) receptor (Levitzki \& Gazit 1995, Zhou et al. 2006), and ERBB2 receptor mRNA levels have been shown to be regulated during follicle development (Kezele et al. 2005b). Therefore, it is possible that signaling through pathways other than that of NT3/NTRK3 are mediating this effect of oocyte loss. When female rats were treated in vivo with AG 879 at doses equivalent to those that caused marked oocyte loss in cultured ovaries, no significant oocyte loss was seen (Fig. 6). Perhaps in vivo the AG 879 compound is metabolized by passage through a detoxifying organ such as the liver or kidney, and thus cannot exert its effect on the ovary and induce oocyte death as it can in culture.

Table 1 Neurotrophin-3 (NT3) regulated genes.

\begin{tabular}{|c|c|c|c|c|c|}
\hline \multirow{3}{*}{ Functional category } & \multicolumn{3}{|c|}{ Microarray signal } & \multirow[b]{3}{*}{$\begin{array}{c}\text { GenBank } \\
\text { accession no. }\end{array}$} & \multirow[b]{3}{*}{ Gene title } \\
\hline & Cont & NT3 & NT3/Cont & & \\
\hline & Raw & Raw & Ratio & & \\
\hline \multicolumn{6}{|l|}{ Cell cycle } \\
\hline RGD1564084 & 54 & 83 & 1.54 & BE100602 & Similar to timeless-interacting protein (predicted) \\
\hline \multicolumn{6}{|c|}{ Cytoskeleton-plasma membrane } \\
\hline Palmd & 63 & 108 & 1.72 & Al176360 & Palmdelphin \\
\hline Epn1 & 78 & 52 & 0.66 & NM_057136 & Epsin 1 \\
\hline Lamc2 & 48 & 76 & 1.57 & BM385282 & Laminin, gamma 2 \\
\hline Cldn3 & 65 & 126 & 1.94 & NM_031700 & Claudin 3 \\
\hline \multicolumn{6}{|l|}{ Development } \\
\hline Nedd4 & 71 & 124 & 1.75 & BF560443 & $\begin{array}{l}\text { Neural precursor cell expressed, developmentally } \\
\text { downregulated gene 4/ubiquitin ligase }\end{array}$ \\
\hline$A p c$ & 70 & 108 & 1.54 & NM_012499 & Adenomatosis polyposis coli/regulates wnt-frizzled \\
\hline Optn & 54 & 81 & 1.50 & AB069907 & Optineurin/regulates $\mathrm{Nf}_{\mathrm{u}}$ Beta signaling and secretion \\
\hline \multicolumn{6}{|l|}{ Immune response } \\
\hline Ly6c & 310 & 198 & 0.64 & NM_020103 & Ly6-C antigen \\
\hline \multicolumn{6}{|l|}{ Proteolysis } \\
\hline Ube4a & 76 & 114 & 1.50 & BF556415 & Ubiquitination factor E4A, UFD2 homolog \\
\hline \multicolumn{6}{|l|}{ Receptor } \\
\hline Plxna3 & 53 & 80 & 1.52 & AW141867 & Plexin A3/Co-receptor for germophorins \\
\hline \multicolumn{6}{|l|}{ Signaling } \\
\hline Hspa4 & 295 & 165 & 0.56 & AFO77354 & Heat shock protein 4 \\
\hline Rheb & 49 & 80 & 1.64 & BE099437 & Ras homolog enriched in brain \\
\hline \multicolumn{6}{|l|}{ Transcription } \\
\hline Myocd & 86 & 49 & 0.57 & BF397140 & Transcription factor myocardin \\
\hline \multicolumn{6}{|c|}{ Miscellaneous and unknown } \\
\hline RGD1305459_pre & 98 & 65 & 0.66 & Al059694 & Similar to KIAA0605 gene product (predicted) \\
\hline RGD1564719_pre & 47 & 76 & 1.60 & Al045149 & Similar to RIKEN cDNA C230052I12 (predicted) \\
\hline RGD1311874_pre & 95 & 63 & 0.66 & BF416240 & Hypothetical LOC300751 (predicted) \\
\hline Expressed sequence tags & 55 & 87 & 1.58 & AA817826 & \\
\hline
\end{tabular}


Further experiments will characterize the mechanisms by which AG 879 affects oocyte viability. The ability to manipulate the primordial follicle pool would be useful to further study ovarian biology and develop therapies for ovarian disease.

Since the NTRK3-selective inhibitor AG 879 induced oocyte apoptosis, a different tyrphostin was used in organ culture experiments to try to inhibit endogenous NT3-NTRK3 signaling. K252a inhibits all three NTRK receptors (NTRK1, NTRK2, and NTRK3). Treatment with K252a decreased spontaneous primordial to primary follicle transition in cultured ovaries (Fig. 7). As the NTRK1 receptor is not expressed in ovaries at this time, and the ligands for the NTRK2 receptor are not expressed (Fig. 3), the inhibitory effect of K252a is likely due to its effect on the NT3/NTRK3 signaling pathway. This supports the hypothesis that NT3 promotes primordial follicle transition. It was noted that the developing follicles of K252a-treated ovaries appeared less healthy than controls. While K252a did not cause a significant decrease in follicle pool size, this observation supports the idea that NT3/NTRK3 signaling may be important to oocyte survival, as was suggested by the results of AG 879 treatment, where oocyte apoptosis occurred. In addition, it is notable that some primordial to primary follicle transition did still occur in the presence of K252a. This indicates that NT3-NTRK3 signaling is probably not absolutely required for follicle transition, an idea supported by the finding that growing primary follicles may be found in mice in which the Ntrk3 gene is knocked out (Spears et al. 2003).

In order to gain some insight into what physiological processes are affected by NT3 signaling, a microarray experiment was performed. mRNA expression in cultured untreated control ovaries was compared with that of NT3-treated ovaries after 2 days. Several genes identified as differentially expressed are known for their functions in the plasma membrane or cytoskeleton. Palmdelphin (PALMD) is associated with eye development and is part of a family of proteins that regulate the shape of the plasma membrane in cells (Lord-Grignon et al. 2006). Epsin 1 (EPN1), laminin gamma 2 (LAMC2), and claudin 3 (CLDN3) are also important in plasma membrane activity or structures, such as endocytotic vesicles or tight junctions (Hewitt et al. 2006, Wang et al. 2006, Weixel et al. 2007, Kato \& Motoyama 2009). This matches what occurs during primordial to primary follicle transition, when significant changes in granulosa cell shape and number must occur. Similarly, granulosa cells are epithelial-derived cells, and the adenomatosis polyposis coli $(A p c)$ gene is known to regulate epithelial cell migration, mitosis and differentiation (McCartney \& Nathke 2008). In addition, APC regulates $\beta$-catenin in the $\mathrm{Wnt} /$ frizzled/ $\beta$-catenin signaling pathway, and this signaling pathway has been shown to be important for ovarian and follicular development (Richards et al. 2002, Ricken et al. 2002). Ubiquitination is also important for proper functioning of the $\mathrm{Wnt} / \beta$-catenin/APC pathway (Voutsadakis 2008), and both Nedd4 and Ube4a are genes regulated by NT3 treatment that are involved in ubiquitination (Caren et al. 2006, Gay et al. 2008). Many of these genes, of course, could also function in pathways unrelated to granulosa cell development. Also noted as changed with NT3 treatment were plexin A3 (Plxna3), known previously for its role in nerve axon guidance (Schwarz et al. 2008), and the transcription factor myocardin (Myocd), previously known for specification of vascular smooth muscle (Long et al. 2007). It is interesting to note that these changes in gene expression have occurred after 2 days of NT3 treatment, before there are any morphological changes in cell number or shape observed in ovarian follicles. Future studies will clarify the roles played by these genes in follicle development.

In these studies, the neurotrophin NT3 has been shown to contribute to promoting the primordial to primary follicle transition in rat ovaries. The actions of NT3 are similar to those of other ovarian growth factors such as KL, LIF, BMP4, BMP7, KGF, PDGF, bFGF, and GDNF (Fortune 2003, Skinner 2005, Visser \& Themmen 2005, Dole et al. 2008). As research reveals more about the regulation of early follicle development, a picture is emerging of a complex network of paracrine and autocrine signaling factors that mediate communication between oocytes, granulosa cells, and surrounding thecal/interstitial cells. Primordial to primary follicle transition and subsequent follicle growth requires the coordinated activity of all these cell types, so it is not surprising that many growth factors are involved. Having many signaling factors involved allows for a complex and compensatory regulation of primordial follicle transition. This process that is vital to reproduction can be tightly controlled, responsive to changing conditions, and redundant so that reproduction continues even if a particular signaling molecule is interrupted. A thorough understanding of early follicle development could make possible the manipulation of this regulatory network, and lead to therapies for some infertility disorders, the extension of reproductive lifespan for domestic animals, and control of the menopausal transition in women.

\section{Materials and Methods}

\section{Organ culture}

Sprague-Dawley rats were obtained from a Washington State University breeding colony. The WSU Animal Care and Use Committee approved all animal procedures. Ovaries dissected from 4-day old female rat pups were maintained in a whole organ culture system on floating filters $(0.4 \mu \mathrm{m}$ Millicell-CM; Millipore Corp., Billerica, MA, USA) in $0.5 \mathrm{ml}$ DMEM-Ham's F-12 medium (1:1, vol/vol; Life Technologies, Inc.) containing $0.1 \%$ BSA (Sigma), 0.1\% albumax (Life Technologies, Inc.), $0.05 \mathrm{mg} / \mathrm{ml}$ L-ascorbic acid (Sigma), and $27.5 \mu \mathrm{g} / \mathrm{ml}$ transferrin (Sigma) in a 4-well culture plate (Nunc plate; Applied Scientific, South San Francisco, CA, USA). Medium was 
supplemented with final concentration $5 \mu \mathrm{g} / \mathrm{ml}$ gentamicin, $3.25 \mu \mathrm{g} / \mathrm{ml}$ streptomycin, and $3.25 \mathrm{units} / \mathrm{ml}$ penicillin to prevent bacterial contamination. Ovaries were treated with no factor (control), NT3 (rh NT3, 50 ng/ml; R\&D Systems, Minneapolis, MN, USA), BDNF (rh BDNF, 50-250 ng/ml; R\&D Systems), NGF (rr $\beta$-NGF, $50 \mathrm{ng} / \mathrm{ml}$; R\&D Systems) or KL/stem cell factor ( $\mathrm{rm} \mathrm{SCF}, 50 \mathrm{ng} / \mathrm{ml}$; R\&D Systems). Alternate treatments include AG 879 and K252a (Calbiochem-EMD Biosciences, Inc., San Diego, CA, USA). One to three ovaries were placed on each filter, and no two ovaries from the same animal were placed into the same treatment group. Culture medium and treatments were replaced every 2 days. After 10 days, ovaries were fixed in Bouin's fixative (Sigma) for $1 \mathrm{~h}$ followed by immersion in $70 \%$ ethanol. Tissues were paraffin embedded, sectioned at $3 \mu \mathrm{m}$, and hematoxylin/eosin stained. The experiments were repeated so that each treatment group contained three to ten different ovaries.

\section{Morphological analysis}

The number of follicles at each developmental stage was counted and averaged in two serial sections from the largest cross-section through the center of the ovary and averaged. Previously, the data obtained from this analysis of two middiameter cross-sections have been shown to provide similar results as analysis of compiled data from all serial sections (Parrott \& Skinner 1999). In addition, total follicle number does not change between treatment groups, unless otherwise indicated in Results. Rather, only the percentage of follicles at each developmental stage changes with treatment (Nilsson et al. 2001, 2002). KL was used as a positive control for the organ culture experiments. If an experiment did not show stimulation of primordial follicle transition with $\mathrm{KL}$ treatment, then that indicated a technical problem had occurred and the data from that experiment were excluded from analysis. In the experiments for this study, if there was no response to $K L$, then there was no response to any other treatment either. Follicles in ovarian cross sections were classified as primordial (stage 0), or developing (stages 1-4: early primary, primary, transitional, and pre-antral) as previously described (Oktay et al. 1995). Primordial follicles consist of an oocyte arrested in prophase I of meiosis that is partially or completely encapsulated by flattened squamous pregranulosa cells. Early transition primary follicles have initiated development (i.e. undergone primordial to primary follicle transition) and contain at least one cuboidal granulosa cell. Primary and pre-antral follicles exhibit one or more complete layers of cuboidal granulosa cells. Four-day old ovaries contain predominately primordial follicles (Parrott \& Skinner 1999, Kezele et al. 2005b). Hematoxylin/eosin-stained ovarian sections were analyzed at $400 \times$ magnification using light microscopy. Follicles containing red eosin-stained oocytes were not counted.

\section{Immunohistochemistry}

Ovary sections from freshly isolated adult or cultured postnatal day 4 (P4) ovaries (unrelated control ovaries cultured for 10 days) were immunostained as previously described (Nilsson et al. 2002) for the presence of NT3 using anti-NT3 antibody (Anti-NT3 rabbit IgG, 1-0.1 $\mu \mathrm{g} / \mathrm{ml}$; Santa Cruz Biotechnology,
Santa Cruz, CA, USA), or for NTRK3 using anti-NTRK3 antibody (Anti-NTRK3 rabbit IgG, 1-10 $\mu \mathrm{g} / \mathrm{ml}$; Santa Cruz Biotechnology). The anti-NT3 antibody was raised against an epitope that was from a portion of the human NT3 protein (Genbank P20783 aa's 110-160) showing 100\% homology to rat NT3. A western blot of human cell lines with this antibody showed two major bands (www.scbt.com/datasheet-547-nt3n-20-antibody.html). The anti-NTRK3 antibody was raised against an epitope from the porcine NTRK protein (GenBank P24786 AAs 770-820) showing 100\% homology to rat NTRK3. Western blots against rat tissues (Ghinelli et al. 2003, Lazar et al. 2004) show only NTRK3 brands. Briefly, $3 \mu \mathrm{m}$ sections were deparaffinized, rehydrated through a graded ethanol series, boiled in sodium citrate (used only in neonatal NT3 immunohistochemistry), quenched in 3\% hydrogen peroxide/ $20 \%$ methanol and $0.1 \%$ Triton-X solution, and then blocked with $10 \%$ goat serum (normal goat serum; Vector Laboratories, Inc., Burlingame, CA, USA) for 20 min prior to incubation with primary antibody for $12 \mathrm{~h}$. Sections were then incubated in $0.1 \%$ Triton- $X$ solution again (not used in neonatal NT3 protocol), washed in PBS and incubated with 1:300 diluted biotinylated secondary antibody for 20-40 min (goat antirabbit IgG; Vector Laboratories, Inc.), washed, and incubated with streptavidin peroxidase (Zymed, San Francisco, CA, USA) prior to colour development with a DAB peroxidase substrate kit (Vector Laboratories, Inc). Following development, sections were dehydrated, cover slips mounted with zylene-based medium (Cytoseal-XYL; Richard Allan Scientific, Kalamazoo, MI, USA), and analyzed at $200 \times$ and $400 \times$ magnification using light microscopy. Negative control experiments were performed using a non-specific primary antibody at concentrations matching NT3 and NTRK3 specific antibodies (Rabbit IgG; Sigma).

$\mathrm{P} 4$ rat ovaries were cultured in the presence or absence of AG 879 for 2 days, then Bouin's fixed, paraffin embedded, and sectioned for apoptosis analysis. Apoptotic cells were detected on duplicate slides by TUNEL assay using a Fluorescein In Situ Cell Death Detection Kit (Roche Applied Science).

\section{PCR}

Uncultured postnatal 4-day old rat ovaries were immersed in Trizol reagent (Sigma) and RNA extracted according to the manufacturer's protocols. RNA samples were DNase treated with the TURBO DNA-free kit (Ambion, Austin, TX, USA) prior to RT of RNA to cDNA according to a standard oligo-dT RT protocol in a reaction volume of $25 \mu \mathrm{l}$. Negative controls for each sample were created at this step by omitting MMLV enzyme in the RT reaction. PCR used the primer pairs described in Supplementary Table 1, which can be viewed online at www.reproduction-online.org/supplemental/. Primers were tested in positive control tissues known to express the genes of interest (adult rat brain, pituitary, or P4 rat testis). Thermocycling conditions were as follows: $95^{\circ} \mathrm{C} 5 \mathrm{~min}, 35$ cycles of $95{ }^{\circ} \mathrm{C} 30 \mathrm{~s}, 60^{\circ} \mathrm{C} 60 \mathrm{~s}, 72{ }^{\circ} \mathrm{C} 30 \mathrm{~s}$, followed by $72{ }^{\circ} \mathrm{C} 5 \mathrm{~min}$. PCR products were electrophoretically analyzed and sequenced to confirm identity. Amplification of the ribosomal protein S2 was used as a reference standard. Ribosomal S2 mRNA expression does not change in ovarian cells regardless of treatment (Kezele et al. 2005a). 


\section{Microarray and bioinformatics}

Postnatal 4-day old rat ovaries were cultured for 2 days in the presence or absence of NT3. Culture conditions were identical to those described for 10-day organ culture experiments. Each sample contained six to ten pooled ovaries, and no two ovaries from the same animal were placed into the same treatment group. For each control and treated sample, three biological replicates were produced using different sets of ovaries. After culture, ovaries were placed into Trizol reagent for RNA extraction as per manufacturer's protocols. RNA was hybridized to the Affymetrix (Santa Clara, CA, USA) Rat 2302.0 gene chips. One chip was used for each biological replicate (i.e. six chips total; three for control and three for treated). The Genomics Core in the Center for Reproductive Biology at Washington State University performed the analysis as previously described (McLean et al. 2002, Shima et al. 2004). Briefly, RNA from control and treated cultured ovaries were reverse transcribed into cDNA, which was transcribed into biotin-labeled RNA. Biotin-labeled RNA was then hybridized to the Affymetrix Rat 2302.0 gene chips. Biotinylated RNA was then visualized by labeling with phycoerythrin-coupled avidin. The microarray chip was scanned on an Affymetrix Gene Chip Scanner 3000 (Affymetrix). The microarray image data were converted to numerical data with GeneChip Operating Software (GCOS version 1.2; Affymetrix) using a probe set target signal of 210. An analysis was performed with GCOS to assess the relative abundance of the transcripts based on signal and detection calls (present, absent, or marginal). The 11 perfect match and 11 mismatch oligonucleotides for a specific gene were used to statistically determine present/absent calls using a one-sided Wilcoxon's signed rank test. In GCOS, Excel files were generated with expression signals and absent/present calls for each probe set. Using the Excel files, $R^{2}$ for each pair of control or treated sample replicates were calculated $\left(R^{2}=0.96-0.99\right)$, indicating negligible total variability between chips, experiments and samples. Quality of chips was assessed in the R-Bioconductor environment and appeared to be satisfactory. Excel files from GCOS were imported into Genespring software (Silicon Genetics, Redwood City, CA, USA) and normalized using the recommended defaults. This includes setting signal values below 0.01 to a value of 0.01 . Unless otherwise indicated, in order for a transcript to be considered present, it had to be both tagged as present in the GCOS present/absent call, and have an expression level $>75$. In order for a transcript to be considered changed between treatment groups, it had to exhibit at least a 1.5-fold change between the means of the treatments and have a Student's $t$-test $P$ value of $<0.05$ between control and treatment samples. Therefore, the data presented are for genes that were determined to be statistically present and found to be statistically different from control with a given treatment.

Previous studies have demonstrated that microarray data are validated with quantitative PCR data (Shima et al. 2004, Kezele et al. 2005b). Owing to the presence of 11 different oligonucleotide sets for each specific gene being used on the microarray versus only a single primer set for a gene in a quantitative PCR, the microarray is more effective at eliminating false positive or negative data and provides a more robust quantification of changes in gene expression.

\section{In vivo treatment protocols}

P4 or P5 old female rats were kept with their mothers and treated by s.c. injection with $50 \mu \mathrm{l}$ of $2 \mu \mathrm{g} / \mathrm{ml}$ AG 879 (Calbiochem-EMD Biosciences, Inc.), or with vehicle alone (sesame oil containing 10\% DMSO). This resulted in a calculated AG 879 concentration in the rat pup of $23.9 \mu \mathrm{M}$, or $7.6 \mathrm{mg} / \mathrm{kg}$ per day. The AG 879 solution was prepared by dissolving AG 879 in DMSO to make a $20 \mu \mathrm{g} / \mathrm{ml}$ stock solution and then diluting the stock solution with sesame oil to make a $2 \mu \mathrm{g} / \mathrm{ml}$ injection solution. Rats were treated daily for 5 days (P5-P9) and killed at ages P9, P13, or P28. Ovaries were fixed in Bouin's solution for $1-2 \mathrm{~h}$ and paraffin embedded prior to sectioning and hematoxylin/eosin staining for morphological analysis. Pubertal female rats (P23 or P26) were weaned from their mothers and treated by i.p. injection with $0.45 \mathrm{mg}$ AG 879 diluted in either $50 \mu \mathrm{l}$ DMSO or $450 \mu$ l sesame oil containing $10 \%$ DMSO. Control animals were treated with vehicle alone. The resulting AG 879 concentrations in the rats were calculated to be $23.5 \mu \mathrm{M}$, or $6.7 \mathrm{mg} / \mathrm{kg}$ per day. Ovaries were fixed in Bouin's solution for $3-4 \mathrm{~h}$ and paraffin embedded prior to sectioning and hematoxylin/eosin staining for morphological analysis.

\section{Statistical analysis}

Organ culture treatment groups were compared using an ANOVA (one-way ANOVA). Following a significant result with ANOVA, treated groups were compared with the control using Dunnet's Multiple Comparison post-hoc test. All statistics were calculated with the help of GraphPad Prism version $4.0 \mathrm{~b}$ software (GraphPad Software, Inc., San Diego, CA, USA).

\section{Declaration of interest}

No conflict or financial interest to declare.

\section{Funding}

This study was supported by a National Institute of Health, NICHD, grant to Dr Michael K Skinner.

\section{Acknowledgements}

We acknowledge the expert technical assistance of Dr Marina Savenkova and Dr Ingrid Sadler-Riggleman. We acknowledge the assistance of the WSU Center for Reproductive Biology Animal Reproduction, Molecular Biology, Genomic and Bioinformatics Core Laboratories. We thank Ms Heather Johnson for assistance in preparation of the manuscript.

\section{References}

Barbacid M 1994 The Trk family of neurotrophin receptors. Journal of Neurobiology 25 1386-1403.

Berkemeier LR, Winslow JW, Kaplan DR, Nikolics K, Goeddel DV \& Rosenthal A 1991 Neurotrophin-5: a novel neurotrophic factor that activates trk and trkB. Neuron 7 857-866. 
Caren H, Holmstrand A, Sjoberg RM \& Martinsson T 2006 The two human homologues of yeast UFD2 ubiquitination factor, UBE4A and UBE4B, are located in common neuroblastoma deletion regions and are subject to mutations in tumours. European Journal of Cancer 42 381-387.

Chao MV, Bothwell MA, Ross AH, Koprowski H, Lanahan AA, Buck CR \& Sehgal A 1986 Gene transfer and molecular cloning of the human NGF receptor. Science 232 518-521.

Cupp AS, Uzumcu M \& Skinner MK 2003 Chemotactic role of neurotropin 3 in the embryonic testis that facilitates male sex determination. Biology of Reproduction 68 2033-2037.

Davies AM, Minichiello L \& Klein R 1995 Developmental changes in NT3 signalling via TrkA and TrkB in embryonic neurons. EMBO Journal 14 4482-4489.

Dechant G 2001 Molecular interactions between neurotrophin receptors. Cell Tissue Research 305 229-238.

Dissen GA, Hirshfield AN, Malamed S \& Ojeda SR 1995 Expression of neurotrophins and their receptors in the mammalian ovary is developmentally regulated: changes at the time of folliculogenesis. Endocrinology 136 4681-4692.

Dissen GA, Romero C, Hirshfield AN \& Ojeda SR 2001 Nerve growth factor is required for early follicular development in the mammalian ovary. Endocrinology 142 2078-2086.

Dissen GA, Romero C, Paredes A \& Ojeda SR 2002 Neurotrophic control of ovarian development. Microscopy Research and Technique 59 509-515.

Dole G, Nilsson EE \& Skinner MK 2008 Glial-derived neurotrophic factor promotes ovarian primordial follicle development and cell-cell interactions during folliculogenesis. Reproduction 135 671-682.

Ernfors P, Wetmore C, Olson L \& Persson H 1990 Identification of cells in rat brain and peripheral tissues expressing mRNA for members of the nerve growth factor family. Neuron 5 511-526.

Faddy MJ 2000 Follicle dynamics during ovarian ageing. Molecular and Cellular Endocrinology 163 43-48.

Fortune JE 2003 The early stages of follicular development: activation of primordial follicles and growth of preantral follicles. Animal Reproduction Science 78 135-163.

Freund-Michel V \& Frossard N 2008 The nerve growth factor and its receptors in airway inflammatory diseases. Pharmacology \& Therapeutics 117 $52-76$.

Gay DL, Ramon H \& Oliver PM 2008 Cbl- and Nedd4-family ubiquitin ligases: balancing tolerance and immunity. Immunologic Research $\mathbf{4 2}$ 51-64.

Ghinelli E, Johansson J, Rios JD, Chen LL, Zoukhri D, Hodges RR \& Dartt DA 2003 Presence and localization of neurotrophins and neurotrophin receptors in rat lacrimal gland. Investigative Ophthalmology \& Visual Science 44 3352-3357.

Gosden RG, Laing SC, Felicio LS, Nelson JF \& Finch CE 1983 Imminent oocyte exhaustion and reduced follicular recruitment mark the transition to acyclicity in aging C57BL/6J mice. Biology of Reproduction 28 255-260.

Harel S, Jin S, Fisch B, Feldberg D, Krissi H, Felz C, Freimann S, Tan SL, Ao A \& Abir R 2006 Tyrosine kinase B receptor and its activated neurotrophins in ovaries from human fetuses and adults. Molecular Human Reproduction 12 357-365.

Hewitt KJ, Agarwal R \& Morin PJ 2006 The claudin gene family: expression in normal and neoplastic tissues. BMC Cancer $\mathbf{6} 186$.

Hirshfield AN 1991 Development of follicles in the mammalian ovary. International Review of Cytology 124 43-101.

Hirshfield AN \& DeSanti AM 1995 Patterns of ovarian cell proliferation in rats during the embryonic period and the first three weeks postpartum. Biology of Reproduction 53 1208-1221.

Hohn A, Leibrock J, Bailey K \& Barde YA 1990 Identification and characterization of a novel member of the nerve growth factor/brainderived neurotrophic factor family. Nature 344 339-341.

Holt JE, Jackson A, Roman SD, Aitken RJ, Koopman P \& McLaughlin EA 2006 CXCR4/SDF1 interaction inhibits the primordial to primary follicle transition in the neonatal mouse ovary. Developmental Biology 293 449-460.

Huang EJ, Wilkinson GA, Farinas I, Backus C, Zang K, Wong SL \& Reichardt LF 1999 Expression of Trk receptors in the developing mouse trigeminal ganglion: in vivo evidence for NT-3 activation of TrkA and TrkB in addition to TrkC. Development 126 2191-2203.
Ikeda Y, Nagai A, Ikeda MA \& Hayashi S 2002 Increased expression of Mullerian-inhibiting substance correlates with inhibition of follicular growth in the developing ovary of rats treated with E2 benzoate. Endocrinology 143 304-312.

Ip NY, Ibanez CF, Nye SH, McClain J, Jones PF, Gies DR, Belluscio L, Le Beau MM, Espinosa R III, Squinto SP et al. 1992 Mammalian neurotrophin-4: structure, chromosomal localization, tissue distribution, and receptor specificity. PNAS 89 3060-3064.

Johnson D, Lanahan A, Buck CR, Sehgal A, Morgan C, Mercer E, Bothwell M \& Chao M 1986 Expression and structure of the human NGF receptor. Cell 47 545-554.

Kato N \& Motoyama T 2009 Relation between laminin-5 gamma 2 chain and cell surface metalloproteinase MT1-MMP in clear cell carcinoma of the ovary. International Journal of Gynecological Pathology 28 49-54.

Kawaguchi-Manabe $H$, leda M, Kimura K, Manabe T, Miyatake S, Kanazawa H, Kawakami T, Ogawa S, Suematsu M \& Fukuda K 2007 A novel cardiac hypertrophic factor, neurotrophin-3, is paradoxically downregulated in cardiac hypertrophy. Life Sciences 81 385-392.

Kezele P, Nilsson EE \& Skinner MK 2005a Keratinocyte growth factor acts as a mesenchymal factor that promotes ovarian primordial to primary follicle transition. Biology of Reproduction 73 967-973.

Kezele PR, Ague JM, Nilsson E \& Skinner MK 2005b Alterations in the ovarian transcriptome during primordial follicle assembly and development. Biology of Reproduction 72 241-255.

Lazar J, Szabo T, Marincsak R, Kovacs L, Blumberg PM \& Biro T 2004 Sensitization of recombinant vanilloid receptor- 1 by various neurotrophic factors. Life Sciences 75 153-163.

Leibrock J, Lottspeich F, Hohn A, Hofer M, Hengerer B, Masiakowski P, Thoenen H \& Barde YA 1989 Molecular cloning and expression of brainderived neurotrophic factor. Nature 341 149-152.

Levi-Montalcini R, Skaper SD, Dal Toso R, Petrelli L \& Leon A 1996 Nerve growth factor: from neurotrophin to neurokine. Trends in Neurosciences 19 514-520.

Levitzki A \& Gazit A 1995 Tyrosine kinase inhibition: an approach to drug development. Science 267 1782-1788.

Long X, Creemers EE, Wang DZ, Olson EN \& Miano JM 2007 Myocardin is a bifunctional switch for smooth versus skeletal muscle differentiation. PNAS 104 16570-16575.

Lord-Grignon J, Abdouh M \& Bernier G 2006 Identification of genes expressed in retinal progenitor/stem cell colonies isolated from the ocular ciliary body of adult mice. Gene Expression Patterns 6 992-999.

Maisonpierre PC, Belluscio L, Squinto S, Ip NY, Furth ME, Lindsay RM \& Yancopoulos GD 1990 Neurotrophin-3: a neurotrophic factor related to NGF and BDNF. Science 247 1446-1451.

McCartney BM \& Nathke IS 2008 Cell regulation by the Apc protein Apc as master regulator of epithelia. Current Opinion in Cell Biology 20 186-193.

McLean DJ, Friel PJ, Pouchnik D \& Griswold MD 2002 Oligonucleotide microarray analysis of gene expression in follicle-stimulating hormonetreated rat Sertoli cells. Molecular Endocrinology 16 2780-2792.

Nico B, Mangieri D, Benagiano V, Crivellato E \& Ribatti D 2008 Nerve growth factor as an angiogenic factor. Microvascular Research 75 135-141.

Nilsson E, Parrott JA \& Skinner MK 2001 Basic fibroblast growth factor induces primordial follicle development and initiates folliculogenesis. Molecular and Cellular Endocrinology 175 123-130.

Nilsson EE, Kezele P \& Skinner MK 2002 Leukemia inhibitory factor (LIF) promotes the primordial to primary follicle transition in rat ovaries. Molecular and Cellular Endocrinology 188 65-73.

Nilsson E, Rogers N \& Skinner MK 2007 Actions of anti-Mullerian hormone on the ovarian transcriptome to inhibit primordial to primary follicle transition. Reproduction 134 209-221.

Oktay K, Schenken RS \& Nelson JF 1995 Proliferating cell nuclear antigen marks the initiation of follicular growth in the rat. Biology of Reproduction 53 295-301.

Papatsoris AG, Liolitsa D \& Deliveliotis C 2007 Manipulation of the nerve growth factor network in prostate cancer. Expert Opinion on Investigational Drugs 16 303-309.

Paredes A, Romero C, Dissen GA, DeChiara TM, Reichardt L, Cornea A, Ojeda SR \& Xu B 2004 TrkB receptors are required for follicular growth and oocyte survival in the mammalian ovary. Developmental Biology 267 430-449. 
Parrott JA \& Skinner MK 1999 Kit-ligand/stem cell factor induces primordial follicle development and initiates folliculogenesis. Endocrinology 140 4262-4271.

Peters H, Byskov AG, Himelstein-Braw R \& Faber M 1975 Follicular growth: the basic event in the mouse and human ovary. Journal of Reproduction and Fertility 45 559-566.

Peters EM, Raap U, Welker P, Tanaka A, Matsuda H, Pavlovic-Masnicosa S, Hendrix S \& Pincelli C 2007 Neurotrophins act as neuroendocrine regulators of skin homeostasis in health and disease. Hormone and Metabolic Research 39 110-124.

Rajah R, Glaser EM \& Hirshfield AN 1992 The changing architecture of the neonatal rat ovary during histogenesis. Developmental Dynamics 194 177-192.

Richards JS, Russell DL, Ochsner S, Hsieh M, Doyle KH, Falender AE, Lo YK \& Sharma SC 2002 Novel signaling pathways that control ovarian follicular development, ovulation, and luteinization. Recent Progress in Hormone Research 57 195-220.

Richardson SJ, Senikas V \& Nelson JF 1987 Follicular depletion during the menopausal transition: evidence for accelerated loss and ultimate exhaustion. Journal of Clinical Endocrinology and Metabolism 65 1231-1237.

Ricken A, Lochhead P, Kontogiannea M \& Farookhi R 2002 Wnt signaling in the ovary: identification and compartmentalized expression of wnt-2, wnt-2b, and frizzled-4 mRNAs. Endocrinology 143 2741-2749.

Romero C, Paredes A, Dissen GA \& Ojeda SR 2002 Nerve growth factor induces the expression of functional FSH receptors in newly formed follicles of the rat ovary. Endocrinology 143 1485-1494.

Rosenthal A, Goeddel DV, Nguyen T, Lewis M, Shih A, Laramee GR, Nikolics K \& Winslow JW 1990 Primary structure and biological activity of a novel human neurotrophic factor. Neuron 4 767-773.

Schwarz Q, Waimey KE, Golding M, Takamatsu H, Kumanogoh A, Fujisawa H, Cheng HJ \& Ruhrberg C 2008 Plexin A3 and plexin A4 convey semaphorin signals during facial nerve development. Developmental Biology 324 1-9.

Segal RA 2003 Selectivity in neurotrophin signaling: theme and variations. Annual Review of Neuroscience 26 299-330.
Seifer DB, Feng B \& Shelden RM 2006 Immunocytochemical evidence for the presence and location of the neurotrophin-Trk receptor family in adult human preovulatory ovarian follicles. American Journal of Obstetrics and Gynaecology 194 1129-1134 (discussion 1134-1126).

Shima JE, McLean DJ, McCarrey JR \& Griswold MD 2004 The murine testicular transcriptome: characterizing gene expression in the testis during the progression of spermatogenesis. Biology of Reproduction 71 319-330.

Skinner MK 2005 Regulation of primordial follicle assembly and development. Human Reproduction Update 11 461-471.

Spears N, Molinek MD, Robinson LL, Fulton N, Cameron H, Shimoda K, Telfer EE, Anderson RA \& Price DJ 2003 The role of neurotrophin receptors in female germ-cell survival in mouse and human. Development 130 5481-5491.

Visser JA \& Themmen AP 2005 Anti-Mullerian hormone and folliculogenesis. Molecular and Cellular Endocrinology 234 81-86.

Voutsadakis IA 2008 The ubiquitin-proteasome system in colorectal cancer. Biochimica et Biophysica Acta 1782 800-808.

Wang H, Traub LM, Weixel KM, Hawryluk MJ, Shah N, Edinger RS, Perry CJ, Kester L, Butterworth MB, Peters KW et al. 2006 Clathrinmediated endocytosis of the epithelial sodium channel. Role of epsin. Journal of Biological Chemistry 281 14129-14135.

Weixel KM, Edinger RS, Kester L, Guerriero CJ, Wang H, Fang L, Kleyman TR, Welling PA, Weisz OA \& Johnson JP 2007 Phosphatidylinositol 4-phosphate 5-kinase reduces cell surface expression of the epithelial sodium channel (ENaC) in cultured collecting duct cells. Journal of Biological Chemistry 282 36534-36542.

Zhou Y, Li S, Hu YP, Wang J, Hauser J, Conway AN, Vinci MA, Humphrey L, Zborowska E, Willson JK et al. 2006 Blockade of EGFR and ErbB2 by the novel dual EGFR and ErbB2 tyrosine kinase inhibitor GW572016 sensitizes human colon carcinoma GEO cells to apoptosis. Cancer Research 66 404-411.

Received 30 April 2009

First decision 2 June 2009

Accepted 7 July 2009 